\section{Once a cigar, always a cigar}

Peter J. Swales

Why Freud Was Wrong: Sin, Science and Psychoanalysis. By Richard Webster. HarperCollins/BasicBooks: 1995. Pp. 673. £24.99, \$35.

Although touted on the jacket as a comprehensive biography, this is not a book that enriches or even attempts to digest our factual knowledge of Freud's life and work. Rather, availing himself of a variety of critical viewpoints advanced in recent years by other authors, Richard Webster seizes on several telling episodes in the origins and history of psychoanalysis to engage in a relentless polemic that, if at times flawed in its simplifications, is nevertheless lethal in its total impact.

At the heart of the author's revisionist synthesis lies a provocative though tenable appraisal of Freud the person. Several writers have previously pointed out a messianic element in Freud's character, but Webster sees it as the very animating principle that goaded Freud onward. Inured from earliest childhood to fulfil his parents' grandiose expectations, Freud sought - and of course found - the kind of secular immortality to be attained only by instating oneself as a worldredeemer.

Consumed by such a vanity, Freud was a scientific somnambulist, blinded to empirical reality by his own wishful agenda, oblivious to what did not match his own preconceptions and ready to appropriate anything that would help to support his madcap speculations a self-deceiver incapable of recognizing the fallacies he perpetrated and the follies he propagated.

According to Webster, Freud's descent into folly began during his early years as a physician when, credulously submitting to the misguided notions of his mentors, Jean-Martin Charcot and Josef Breuer, he persistently misdiagnosed as psychogenic an array of mysterious somatic symptoms that neurologists today would not fail to recognize as indicative of underlying organic pathology - closed head injuries, temporal-lobe epilepsy, syphilis and so on. Positing a discrete neurophysiological syndrome of a psychical origin, often following traumas, Freud routinely deemed such symptoms to be hysterical - by Webster's reckoning, a grab-bag diagnosis of no objective merit that served merely to mask the then profound neurological ignorance.

Constrained by the limits of the knowledge of his epoch, and without the benefit of modern medical equipment, Freud surely committed such blunders often enough. But the author fails to give due consideration to alternative explanations, such as the real possibility that many of Freud's early patients were simply casualties of life, whose somatic symptoms he then managed to vanquish with words only because they were products of makebelieve in the first place.

Take, for example, the little-observed

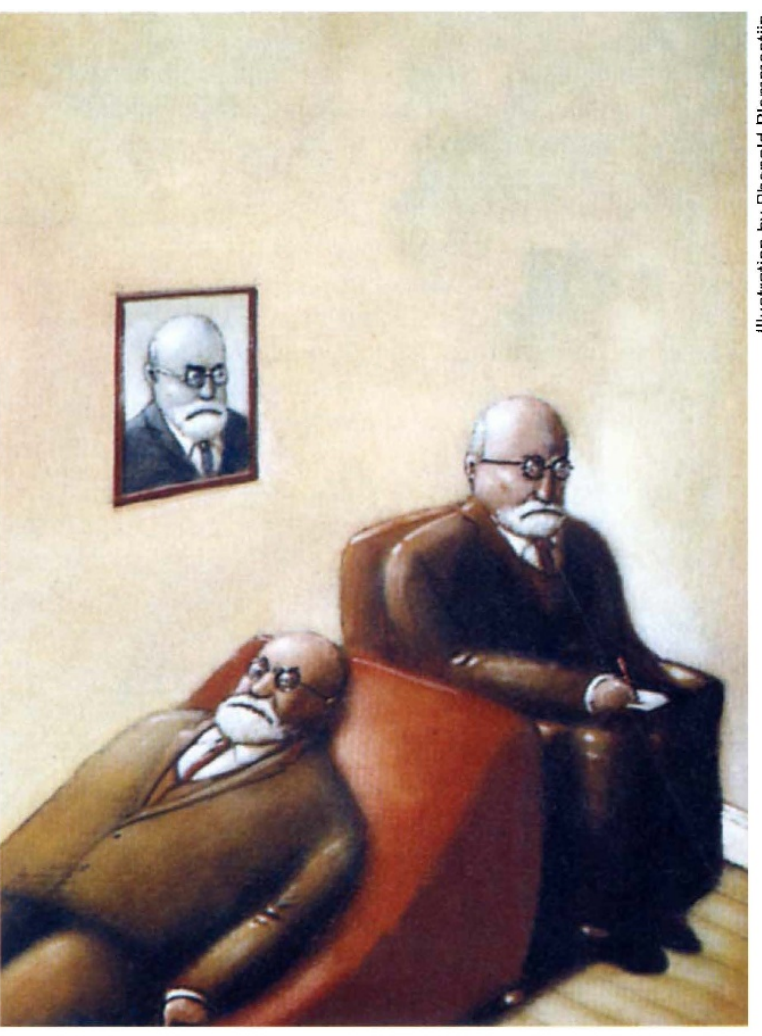

fact that, on termination of her treatment, Breuer's patient Anna O. - the subject of the legendary 'first case' of psychoanalysis - confessed that she had simulated her symptoms. But Breuer, who had devoted himself to her care daily for most of 18 months, would hear none of it; and he would later construe her admission as consistent with a cure of her hysteria. Webster, tenacious in his organic absolutism, disregards this ominous episode.

Although not himself a man of medicine - his own background is in English literature - the author does not doubt that Anna O. was afflicted by a severe neurological disorder, yet he supposes its array of florid symptoms underwent spontaneous remission one after another. Moreover, because the patient had naturally discussed all of these with her physician, she and Breuer - and, later, Freud too - fell into the post hoc fallacy of supposing that the "talking cure" was actually responsible for their disappearance.

By gainsaying Freud in such a takeit-or-leave-it fashion, and by ruthlessly exposing many empirical and logical absurdities in his claims, Webster generally makes a good case that Freud went awfully wrong. $\mathrm{He}$ is far less successful when he seeks to belittle Freud by minimizing his originality, for here the reader is offered only wearisome variations on a theme. According to Webster, the tenets of Freudian theory are merely new editions of select facets of the JudaeoChristian tradition - so psychoanalysis is ultimately explained away as being no more than a disguised and secular version of Western theology, with Freud, of course, as godhead.

From childhood on, Freud was indeed preoccupied with biblical motifs, and their influence on him is not to be underestimated. Before long, however, Webster's attempt to frame Freud's thoughtsystem in this context begins to ring hollow for, in truth, his interpretation is merely a substitute for a closer appreciation of Freud's wide-ranging sources.

If mankind is truly to be cured of psychoanalysis - and if we are all to be cured of having repeatedly to contradict Freud - then we need to understand adequately the man and his creation. Some familiarity with the history of ideas in nineteenth-century Germany and Austria is therefore indispensable. But Webster's frame of reference, as reflected by his literary quotations and bibliography, is so Anglocentric as to provoke in the more attuned reader an acute sense of cultural dislocation.

Webster portentously disposes of Freud's most intellectually formative years, his decade of studies in biology and medicine, in half a page. $\mathrm{He}$ also eschews dozens of Freud's published letters from that period that identify thinkers of seminal importance in the shaping of his Weltanschauung - Gotthold Ephraim Lessing, Johann Wolfgang von Goethe, Jean Paul, Ludwig Feuerbach and Ernst Haeckel, to name but a few. Inevitably, such remissness makes the subsequent inception and evolution of psychoanalytic theory more difficult to comprehend.

Freud would claim that his psychosexual theories were compelled by clinical observations - that, reluctantly, he had been forced to confront sexuality in investigating psychopathology on his couch. Following Frank Sulloway, Webster rightly emphasizes how Freud's theory-building after 1896 was mainly inspired by assumptions smuggled in from contemporary biology. 
In particular, Webster stresses the importance for Freud of Haeckel's "biogenetic law" - the by now longdiscredited principle that ontogeny recapitulates phylogeny. But, oblivious to Freud's background in biology - it was in fact Haeckel's brand of Darwinism that had stimulated Freud to take up studies in science in the first place - Webster supposes it was Wilhelm Fliess, Freud's biologist friend, who equipped him, late in the day, with such a viewpoint. And this helps to obscure a much larger truth.

Webster is astute in perceiving as fundamental to Freudian interpretation what he dubs Freud's "theory of correspondences" - a mode of ontogenetic reductionism accomplished by appeals to homologies and analogies whereby, in Freud's scheme of things, every silk purse can inevitably be unmasked as nothing but its "prototype" or "imago" - that is, a sow's ear. And he recognizes a basic epistemological kinship between the heuristic styles of Freud and Fliess - for, throughout his writings on biorhythms, Fliess also uses an audacious reductive methodology based on the principle of the prototype (Webster's "lowest common denominator").

But the author supposes that Freud arrived at this mode of interpretation in his clinical practice in the years after 1910 , whereas in fact it had by then long been the quintessence of the Freudian style; and he fails to appreciate the origins of this approach in the unconstrained morphological conjecture characteristic of comparative anatomists and zoologists in Germany from Goethe to Haeckel luminaries whose works were fundamental in shaping the thought systems of Freud, Fliess and several of their late nineteenth-century scientific contemporaries.

Historically speaking, the doctrines of Freud and Fliess are properly seen as bastard children of nineteenth-century morphological science. But this means, in effect, that both men's thought systems are throwbacks to the Naturphilosophie of the Romantics and the "natural supernaturalism" of the German idealist philosophers (re-tailored for the Anglophone world by Thomas Carlyle, the Alpine Christian). And it is no coincidence that basic to their programmes was precisely the sort of secularization of biblical motifs that Webster here attributes to Freud.

A less polemical and more informative "critical intellectual biography", then, would trace the materialistic pantheism of Freudian theory to its more immediate sources (Carlyle among them). And such a book - one that would inevitably comprehend Freud's life as one actually lived on the model of a Bildungsroman - might well vindicate Webster in his identification of Freud as Messiah, showing him to be more on target in some of his intuitions than even he himself knows.
With its trenchant assault on the empirical and logical foundations of Freud's theory-building and its cogent depiction of psychoanalysis as a religion, Webster's book, albeit largely derivative, stands as a valid and important addition to the literature. Its value as a contribution to history is vitiated, however, by the author's lamentable ignorance of the cultural and scientific contexts in which Freud worked and of which he was very much a product, and his wanton disregard of much of the primary material that illuminates his intellectual genealogy.

Emboldened by his demolition work and concerned to write more than just another polemic against Freud, Webster ends by trumpeting an oddly messianic note of his own - that out of the ashes of psychoanalysis a new psychology can now arise on the wings of neo-Darwinism. But his phoenix fails to take flight, for he omits to say what such a psychology might consist of and to what epistemology it might submit. Furthermore, in the wake of the demise of both Marxism and Freudianism, to invest in the basic principle that, with time, through natural selection, a sow's ear can become a silk purse is surely to bet against the odds - this at the very least.

Peter J. Swales, an historian of psychoanalysis, is at 285 Mott Street, New York, New York 10012, USA.

\section{Ancestral patterns}

\section{Jane Maienschein}

Biology Takes Form: Animal Morphology and the German Universities, 18001900. By Lynn K. Nyhart. University of Chicago Press: 1995 Pp. 414. \$75, $£ 59.95$ (hbk); $\$ 27.50$, £21.95 (pbk).

TwENTY years ago, Garland Allen published his Life Science in the Twentieth Century. The first chapter included a seven-page section on "The Science of Morphology", which Allen defined in terms of the study of living forms, tracing common evolutionary ancestors and using the comparative method to reconstruct phylogenies. Ernst Haeckel and August Weismann led the way in a field characterized by speculative theorizing. Then, according to Allen, a younger generation rejected this speculation and phylogenizing, producing a "revolt from morphology". In turn, a younger generation of historians challenged Allen's avowedly Marxist insistence on revolution and suggested a more gradual, evolutionary interpretation of change.

While this discussion was developing, Lynn Nyhart was an undergraduate at Princeton, going on to graduate school at the University of Pennsylvania. She felt that neither Allen's short sketch nor the responses were capturing the great diversity of German morphology. Never an established university discipline, morphological study nonetheless gained a different kind of prominence in German intellectual discussions than either Allen or his critics (who focused on American biology and its German roots) had fully appreciated. Rather than attacking these interpretations, Nyhart instead convincingly shows that we need to go further to explore more of what had been the lively study of morphology - and that it matters for our understanding of science. By offering her compelling study in the spirit of extending scholarship rather than demanding that her own interpretation replace all others, she reveals a healthy open-mindedness. The overall result should be an improved understanding of the scientific enterprise and how to study it. Her book is to be applauded for its good sense and provocative suggestions for valuable new research directions, and should stand as a worthy companion in the German study of form to classic explorations of Darwinian evolution, medical anatomy and embryology.

As Nyhart points out, recognizing the contributions of dozens of researchers as they moved among German universities over a century yields a different perspective than the study of only a single person, place or set of scientific contributions at a particular time. Although she thus lacks detail about the scientific contributions, she sees generational shifts that would otherwise remain invisible. She recognizes that older generations of scientists do not die as quickly as generations of new researchers and approaches appear, and that generations thus overlap intellectually rather than later generations neatly replacing earlier ones. The replacement may be further confounded by lack of institutional opportunities.

In the nineteenth century, E. S. Russell's three stages of morphology prevail (as elaborated in his 1916 book Form and Function): idealism gives way to evolutionary morphology, then to causal experimental analysis. Yet the stages overlap, and the intellectual successes do not map neatly to institutional successes. For example, Haeckel gained prominence for his public espousal of Darwinian evolution or materialistic monism, yet never established an effective research 'school' to produce students to follow and spread his 'truth'.

Nyhart touches on several intriguing questions. How can we explain the intellectual success of the morphological programme when it was never refined as a discipline with university chairs or journals in Germany? Why did Haeckel and his close friend Carl Gegenbaur look like the leaders when they had few students and little direct institutional influence in 